\title{
Las palabras femeninas del mal en el Libro de Apolonio
}

\section{(The feminine words of evil in the Libro de Apolonio)}

\author{
CARINA ZUBILLAGA \\ carinazubillaga@hotmail.com \\ Universidad de Buenos Aires - SECRIT (IIBICRIT-CONICET)
}

Fecha de recepción: 28 de octubre de 2019

Fecha de aceptación: 9 de mayo de 2020

Resumen: El discurso de Luciana y Tarsiana en el Libro de Apolonio (las virtuosas esposa e hija del héroe de la historia) se contrapone a las palabras del resto de las mujeres en el poema. La visión clerical negativa acerca de la palabra femenina se analiza en el presente trabajo particularmente en la figura de la nodriza de la joven hija del rey Antíoco y de Dionisa como madrastra de Tarsiana, a partir de los motivos del consejo y cuidado femeninos que ambas mujeres traicionan en el vínculo de sus palabras con lo falso, lo diabólico y el mal en general.

Palabras clave: Palabra. Mal. Mujer. Libro de Apolonio.

Abstract: Luciana and Tarsiana's speech in the Libro de Apolonio (the virtuous wife and daughter of the hero of the story) contrasts with the words of the rest of the women in the poem. The negative clerical vision about the feminine word is analyzed in the present work particularly in the figure of the nurse of the young daughter of King Antiochus and Dionisa as stepmother of Tarsiana, based on the motives of female advice and care that both women betray in the link of their words with the false, the diabolical and evil.

Keywords: Word. Evil. Woman. Libro de Apolonio.

El Libro de Apolonio, poema castellano de principios del siglo XIII perteneciente a la escuela poética del "mester de clerecía" y parte -junto con el Libro de Alexandre- de la recepción de la materia de la Antigüedad en el Medioevo hispánico, es una singular historia de aventuras en la que la ética cristiana que 
subyace al texto ${ }^{1}$ determina heroísmos alejados de una huella efectivamente caballeresca y más cercanos a la impronta cortés y letrada de la clerecía que le da origen $^{2}$.

A pesar de que es Apolonio, sin dudas, el héroe indiscutido de esta historia, su esposa Luciana y su hija Tarsiana también tienen un protagonismo esencial en el texto, debido a la preponderancia de la familia como eje de la estabilidad individual y social propuesto en el poema y a la idea de prueba cristiana que se diversifica en las figuras masculinas y femeninas textuales, promoviendo y desarrollando las aventuras singulares de cada miembro de la familia luego de su separación en la historia. Las peripecias particulares de Luciana y Tarsiana en el desarrollo textual permiten la configuración de una heroicidad femenina paralela a la de Apolonio como hombre, pero distintiva y capaz de propiciar otras situaciones y líneas argumentales, en particular aquella asociada a la defensa de la castidad como la virtud más destacada en las mujeres del período.

La constitución de Luciana y Tarsiana como heroínas en defensa de su castidad las posiciona en el poema como ejes modélicos de la virtud cristiana, alejándolas tanto de la vara medieval en cuanto a la consideración general de las mujeres como del resto de las mujeres presentes en la obra. En esas otras mujeres que aparecen en el poema, fundamentalmente su lenguaje da cuenta de una visión clerical femenina en función de su estatus genérico ligado al peligro, la tentación y, por qué no decirlo, la maldad.

El propósito del presente trabajo será entonces analizar la conformación del discurso de esas malas mujeres en el Libro de Apolonio, en oposición al lenguaje virtuoso de las heroínas de la historia, para intentar profundizar en la problemática de la representación de lo femenino en el texto a partir de abordajes previos propios centrados en las figuras de Luciana y Tarsiana ${ }^{3}$.

La desconfianza clerical hacia las mujeres, base de una aproximación medieval a su figura como tentadoras - a imagen de Eva-, perpetúa modelos ligados al mal; y esa proximidad entre lo femenino y la maldad se testimonia en el retrato tanto

\footnotetext{
1 "Lo que es constante en el Libro de Apolonio es el sistema cristiano de valores dentro del cual el poeta encaja la acción y los personajes" (Deyermond 1989: 162).

2 Ver los estudios ya clásicos del "mester de clerecía" de Rico (1985) y de Uría Maqua (2000). El aporte más reciente de Weiss (2006) permite ampliar la consideración de los textos de clerecía más allá de aquellos compuestos en cuaderna vía, focalizando en el carácter mediador y de agencia cultural de la tarea de los clérigos.

${ }^{3}$ Este artículo complementa mi reciente trabajo publicado en Mirabilia (Zubillaga 2019). Mientras la aproximación allí se centraba en la voz femenina en el Libro de Apolonio, focalizando particularmente las emisiones vocales de los personajes de Luciana y Tarsiana, en este caso se trata específicamente del contenido de la palabra femenina - no su sonido- en relación con la maldad de las otras mujeres en el poema.
} 
del cuerpo como de las palabras de las mujeres en tantas producciones del período ${ }^{4}$. Es lógico, en este sentido, que en un ámbito en el que "las mujeres tenían que convivir con las palabras de aquellos hombres a quienes una determinada organización social y una precisa ideología habían confiado el gobierno de los cuerpos y de las almas femeninas" (Casagrande 1992: 93) su propio discurso en textos de raigambre clerical reprodujera de alguna forma esas palabras.

La concepción negativa de la palabra femenina está determinada, en parte, por la dificultad de su control; una regulación religiosa y/o social que puede, de acuerdo con esto, alcanzar los espacios públicos, pero se ve imposibilitada de acceder a la custodia de lo privado:

Por muy custodiadas que estén en los gestos, la vestimenta, los alimentos, las actividades manuales y las obras de misericordia, las mujeres hablan y, según los predicadores y los moralistas, hablan demasiado y mal: mienten con habilidad, se intercambian maldiciones, pelean continuamente, son insistentes y quejicas, no dejan nunca de parlotear (Casagrande 1992: 123).

Frente a tal consideración negativa, el ideal clerical acerca de la palabra femenina supone, si no el deseable silencio, sí una esperable parquedad y sujeción a la voluntad masculina, ya sea de padres, maridos o confesores:

Pocas y medidas palabras interrumpen, pues, la atmósfera de silencio en que se moverá la mujer ideal de los predicadores y de los moralistas: una sumisa intercalación de humildes preguntas y de obsequiosas respuestas con los maridos y los padres, algunos meditados consejos y ciertas calmas admoniciones dirigidas a los familiares y a la servidumbre, una repetitiva y edificante lectura de los textos sagrados; y a veces, según los tiempos y los modos establecidos por la Iglesia, una sincera y completa confesión de los pecados, con gran atención en la elección del confesor y evitando con cuidado cualquier complacencia en la narración de las propias vicisitudes pecaminosas, como si de una fábula se tratara (Casagrande 1992: 127).

\footnotetext{
4 Ver, al respecto, los aportes recientes en el marco de los estudios de género de Pastor de Togneri 2000, Brozyna 2005 y Schaus 2006, entre otros. Un interesante abordaje, específicamente sobre la caracterización lingüística del discurso femenino medieval castellano, es el de López Izquierdo 2004, quien analiza otros personajes y textos no referidos en este artículo.
} 


\section{CARINA ZUBILLAGA}

En el Libro de Apolonio, en este sentido, existe una clara distinción entre la palabra de Luciana y Tarsiana y el discurso de las demás mujeres, que se analizará focalizando el lenguaje femenino generalizado en la obra -más allá del particularizado en las heroínas- como un lenguaje maligno, artero, capaz de promover o preservar el pecado como la cifra esencial del mal presente en la historia. Las palabras de Luciana y Tarsiana constituyen la medida de un lenguaje ligado al saber clerical privilegiado en el texto como camino de la virtud y, por ello, efectivamente asociado a la escritura como práctica letrada; un lenguaje, además, vinculado a los valores de la verdad y la santidad frente a la mentira. Las palabras de las demás mujeres, en cambio, pueden hipotetizarse como próximas a la oralidad en diversas formas y esencialmente mentirosas, en relación con lo demoníaco o lo diabólico como referencia principal al mal.

La primera voz femenina que aparece en el Libro de Apolonio es la del aya de la joven hija del rey Antíoco, quien padece el incesto con su padre como un mal que la sume en la vergüenza y el silencio. Frente a su pesadumbre, su nodriza representa la figura del mal consejo, que intenta preservar el pecado secreto de la corte de Antioquía:

Fija, dixo, si vergüença o quebranto prisiestes, non avedes culpa, que vós más non pudiestes; esto que vós veyedes en ventura lo oviestes.

Alegratvos, señora, que vós más non pudiestes.

Demás yo vos consejo, e vós creyérmelo devedes, al rey vuestro padre vós non lo enfamedes; maguer grant es la pérdida, más val que lo calledes que al rey e a vós en mal preçio echedes $(9-10)^{5}$.

El trato cercano y familiar del ama de crianza con la joven se asume como la relación que suple la ausencia materna de la corte, aunque claramente el consejo no es el propio de una madre, sino antes bien el reaseguro de la perpetuación de un orden establecido basado en la disrupción familiar-social y su secreto. Las palabras de la nodriza resultan, por lo tanto, palabras malignas, pues buscan preservar el pecado que infesta a Antioquía y que toda la corte conoce, a pesar del ocultamiento. Y son, además, palabras asociadas a la oralidad y lo tradicional, a través del motivo del secreto y su relación en el poema con la adivinanza acerca del incesto.

${ }^{5}$ La transcripción corresponde a mi edición del poema, parte de la edición conjunta del Ms. Esc. K-III-4 (Zubillaga 2014). Luego de cada cita, se consignan las estrofas y/o versos correspondientes. 
La adivinanza como núcleo enigmático primario del Libro de Apolonio permite mantener oculto el incesto ante los pretendientes de la hija de Antíoco, quienes son asesinados al no poder resolver un enigma cuya resolución es asimismo inaceptable para el monarca, como sucede efectivamente con la respuesta acertada de Apolonio. En tanto héroe letrado, Apolonio sí responde el enigma, pero la verdad es negada por el rey incestuoso, unificando de esa forma en el pecado las figuras de la mentira y el secreto. Deyermond analiza la relación del tabú del incesto y la adivinanza en tanto motivo folclórico tradicional, estableciendo que "El carácter erudito y cortesano de Apolonio contrasta fuertemente con las primitivas situaciones folklóricas en que está implicado" (1968-69: 148). Lo tradicional u oral, asociado de esta forma a las palabras mentirosas, asume un cariz de negatividad que solo el componente heroico letrado logrará revertir, resignificándolo a partir de una valoración de la sabiduría representada por lo clerical.

La oposición vejez-juventud resaltada en el poema resulta asimismo resignificada a través de las palabras aconsejadas por la nodriza a la joven a quien criara, ya que la voz de la edad -en general ligada también tradicionalmente a la sabiduría- solo emite palabras que promueven - en la falsedad del consejo- el pecado que es sinónimo del mal: "El pecado, que nunca en paz suele seyer, / tanto pudo el malo bolver e rebolver / que fiço a Antiocho en ella entender" (6ac). La figura tradicional del anciano sabio, o la variante aquí presente del ama vieja consejera, se revierte a través del consejo malévolo cifrado en la palabra femenina.

No siempre, sin embargo, la palabra de la vejez está vinculada a lo maligno en el poema, ya que el aya de Tarsiana representa, de manera totalmente opuesta, la medida del buen consejo femenino. Esta nodriza encarna el poder de admonición de la palabra femenina, considerada como forma esencial de instrucción de las mujeres en especial con respecto a los jóvenes o, como sucede específicamente en este caso, las jóvenes.

Justo antes de morir, el ama le revela a Tarsiana su origen, desconocido por ella:

De Pentápolin fuestes de raíz e de suelo, al rey Architrastres oviestes por avuelo; su fija Luçiana, ementárvosla suelo, esa fue vuestra madre que delexó gran duelo.

El rey Apolonio, un noble cavallero, señor era de Tiro, un reçio cabdalero; ese fue vuestro padre, agora es palmero, 
por tierras de Egipto anda como romero (359-360).

Aquí la vejez de la nodriza simboliza el reservorio de la memoria familiar de Tarsiana; sus palabras, en consecuencia, constituyen la cifra del bien y la verdad familiar. El registro, sin embargo, sigue estando asociado a la oralidad, lo que queda claro en el cariz de la enseñanza impartida, que debe ser recordada por la joven. Recién cuando la verdad pasa de una a otra, la anciana muere, asociándose de manera significativa la hora de su muerte con la pérdida de la lengua y la transmisión acabada de sus palabras:

Quando esto le ovo dicho e enseñado, e lo ovo la niña todo bien recordado, fue perdiendo la lengua e, el ora llegando, despidióse del mundo e de su gasañado (363).

En tanto las palabras de la nodriza de la hija de Antíoco representaban la maldad que encubría el pecado del incesto que infestaba la familia y la corte entera de Antioquía, las palabras de Licórides a Tarsiana son referencia del bien constitutivo de la propia historia. Ambas amas de crianza sustituyen a la madre ausente de las jóvenes, una efectivamente muerta y la otra dada por muerta, pero reconfiguran de manera absolutamente opuesta la función del consejo materno, poniendo de relieve ese consejo femenino como parte de un orden -o desordenfamiliar y social más extendido que las figuras individuales.

En el primer caso, el de la corte de Antioquía, solo el rey tiene nombre propio; ni la hija incestuosa ni su aya poseen un nombre que las identifique más allá de su correspondiente rol femenino. La funcionalidad social de sus figuras queda clara en ese silencio del poema, semejante al ocultamiento del incesto subsumido bajo la figura del pecado que corroe internamente a toda la corte. En el caso opuesto, Licórides sí posee nombre propio, aunque su papel como criada vieja también está subsumido en la figura de la memoria: individual, familiar, pero esencialmente social, al aludir a través de sus palabras a un pasado y un origen ligado de manera evidente a las cortes de Tiro y de Pentápolis.

Si el consejo de las nodrizas a las jóvenes es parte de la crianza que vincula a la vejez -o madurez- con la juventud, remitiendo de forma indirecta a su cuidado a partir de la falta de la figura materna en ambos casos, esa acción de cuidar es asumida en el poema luego cabal y directamente por Dionisa, la burguesa a quien Apolonio deja a cargo de su hija Tarsiana cuando decide partir a Egipto como romero. Tanto ella como su esposo Estrángilo acogen a la recién nacida cuando Apolonio, abrumado por la aparente muerte de su esposa, decide alejarse de Tarso: 


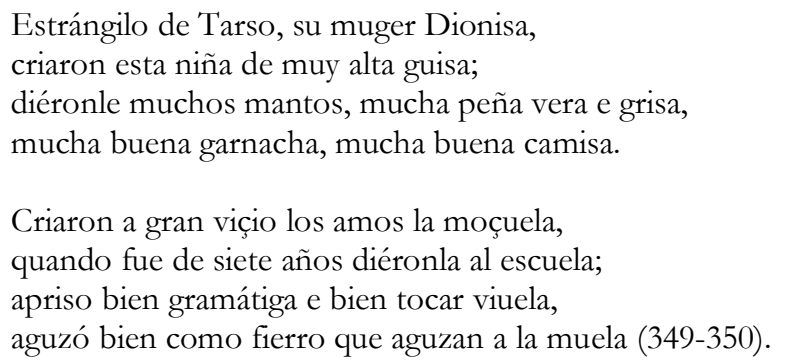

La función de la crianza, condensada en el cuidado tanto físico como moral e intelectual de la niña, se pone llamativamente en suspenso en la juventud de Tarsiana a causa de los dichos (identificados singularmente como "conseja") de los habitantes de la ciudad que distinguen a la joven tanto de su madrastra como de su hermanastra:

Por ó quier que pasavan, por rúa o por calleja, de doña Tarsiana fazián todos conseja; dizián que Dionisa nin su conpañera non valién contra ella una mala erveja (367).

Son las palabras sinceras de quienes las ven juntas las que desencadenan los celos de Dionisa, a partir de la escucha de esa voz colectiva; esos celos, a su vez, se manifiestan mediante su propia voz, interior en principio, planificando la muerte de la doncella al considerar los beneficios -en particular económicosque esta le acarrearía:

Dizié entre su cuer la mala omiçida:

"Si esta moça fuese de carrera tollida, con estos sus adobos que la fazen vellida casaría mi fija, la que hove parida" (370).

Las palabras de Dionisa, antes de consejo y cuidado para con Tarsiana, se transforman en palabras internas, no dichas pero recurrentes, que refieren el descuido absoluto de su hijastra: la determinación y planificación de su asesinato. Esa voz interior repetitiva y malvada se particulariza en el poema en este desarrollo del plan de la muerte de la joven: "Comidiendo la falsa en esta traición" (371a), "Asmó la mala fembra lo que bien entendredes" (372c), que busca concretarse en el encargo secreto de la muerte al rufián Teófilo: "Llamólo luego ella en muy gran poridat, / fízole entender toda su voluntat" (373ab). 
Una vez que el propio Teófilo le miente a Dionisa acerca de que ha cumplido el encargo, cuando en realidad no ha podido hacerlo, ella le niega el pago de sus servicios esquivando su responsabilidad en el hecho y duplicando, con la falsedad de sus palabras, la traición generada por ellas:

Recudió la dueña, mas no a su sabor:

" $¡ V i ́ a$, dixo, daquende, falso e traidor!

As fecho omeçidio e muy gran traiçión,

non te prendré por ello vergüença nin pavor.

Tórnate al aldeya e piensa de tu lavor,

si no averás luego la maldiçión del Criador;

si más ante mí vienes, reçibrás tal amor

qual tú feziste a Tarsiana e non otro mejor” (388-389).

La mentira, en tanto representación consumada de la maldad femenina en el personaje de Dionisa, vuelve a ser el eje textual cuando Apolonio regresa a Tarso y la mujer le dice que su hija ha muerto. Ella en verdad cree estar en lo cierto, según lo que Teófilo le ha dicho también falsamente, y su mentira gira de forma específica alrededor de las circunstancias de esa presunta muerte por motivos naturales:

Recudiól' Dionisa, díxol' grant falsedat:

"Rey, de tu fija esta es la verdat:

al coraçón le priso mortal enfermedat,

passada es del sieglo, esta es la verdat" (438).

La traición de la mujer no se queda solo en las palabras, sino que construye una sepultura falsa para la joven; este hecho le permite al narrador la identificación final del accionar femenino con lo diabólico: "Cosa endiablada, la burçesa Dionisa, / ministra del pecado, fizo grant astrosía" (445ab). Apolonio, sin embargo, al llegar a esa sepultura con la intención de llorar a su hija no puede hacerlo, lo que lo lleva a dudar de la veracidad de su muerte:

Tornó contra sí mismo, començó de asmar:

“Ay, Dios!, ¿qué puede esta cosa estar?

Si mi fija Tarsiana yoguiesse en este logar,

non devién los mis ojos tan en caro se partir.

Asmo que todo aquesto es mentira provada,

non creyo que mi fija aquí es soterrada;

mas o me la han vendida o en mal logar echada. 
Seya, muerta o biva, a Dios acomendada" (449-450).

En un sugestivo vínculo del lenguaje y el cuerpo, frente a la mentira de la palabra de Dionisa, el cuerpo parece reaccionar con su propio lenguaje; en este caso, la incapacidad de Apolonio de llorar frente al reconocimiento de otro cuerpo, el de su hija, que realmente no está allí.

En tanto las palabras de Dionisa son mentirosas, lo que en verdad hacen es encubrir su voz interior -la verdaderamente malvada- ${ }^{6}$. Esas palabras relacionadas con el mal, a través de la planificación del asesinato de Tarsiana y luego de su encubrimiento, también están asociadas a la oralidad, por su falta de registro, y esencialmente a los componentes de tradicionalidad propios de la figura de la madrastra como una de las representaciones femeninas populares del mal. Incluso las únicas palabras de Dionisa ligadas a la escritura, aquellas que escribe en la falsa lápida de Tarsiana, dan cuenta del registro de la vida y la impronta de la muerte humanas como discurso tradicional, aquí igualmente mentiroso:

Fizo sobre la piedra las letras escrevir: "Aquí fizo Estrángilo a Tarsiana sobollir, fija de Apolonyo, el buen rey de Tir, que a los XII años abés pudo sobir" (446).

En su relación con el registro escrito, las palabras de las heroínas de la historia asumen en cambio un carácter asociado a la verdad. Tanto en Luciana como en Tarsiana, lo bueno y lo verdadero parecen encontrar su expresión privilegiada en la escritura como medio vinculado no solo con la sabiduría letrada clerical, sino en especial con otras virtudes como la bondad e incluso la santidad.

La ligazón de Luciana con la palabra, en particular la escrita, resulta innegable en el Libro de Apolonio, al punto que Desing la caracteriza como "the most significant figure in the poem in terms of text, not only for her literal journey in the company of the written word, but also for her skillful uses of texts throughout the poem" (2011: 3).

Los conocimientos letrados de Luciana como princesa de Pentápolis quedan claros ya en su presentación inicial, cuando se caracteriza su desempeño musical a través de la maestría de la ejecución. De manera significativa, incluso el manejo

${ }^{6}$ Es preciso resaltar que en tanto esa voz interior de Dionisa es la cifra de su maldad, la voz interior de Apolonio que lo lleva a dudar de la muerte de su hija es la representación tanto de su sabiduría como de lo verdadero. 
de la vihuela se compara con las palabras como marco de referencia explícito de sus saberes:

Faziá fermosos sones e fermosos debailados, quedava a sabiendas la boz a las vegadas; faziá a la viuela dezir puntos ortados, semejava que eran palabras afirmadas (179).

Será sin embargo más adelante, cuando se la requiera de amores, la oportunidad en la cual la relación de Luciana con la palabra se pondrá totalmente de manifiesto, con la carta enigmática con la que contestará la propuesta matrimonial de sus pretendientes. Frente al primer enigma de la historia, la adivinanza que encubría el incesto del rey Antíoco y su hija y que tanto por forma como por temática se enlazaba con lo tradicional, esta carta de Luciana -de registro escrito- pondrá de relieve los lazos del enigma, el amor y la clerecía letrada en el desarrollo de la historia:

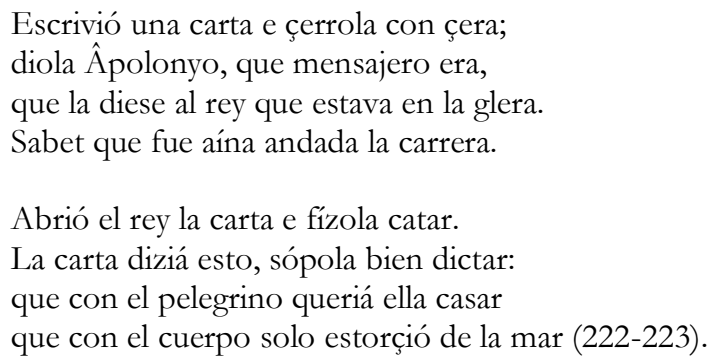

La palabra resulta, de este modo, el vehículo privilegiado mediante el cual la princesa manifiesta su amor oculto por el héroe, que se vuelve mensajero de esa escritura que al mismo tiempo se refiere a él. Esa palabra escrita que cifra sus auténticos sentimientos es muestra y develamiento de esa verdad para aquel que sabe interpretarla de forma precisa, como en este caso Apolonio.

En el momento del reencuentro de Luciana y Apolonio, el recuerdo de esa palabra será, asimismo, el medio declarado de reconocimiento entre ambos:

Yo só la tu muger, la que era perdida, la que en la mar echeste, que tienes por transida; del rey Architrastres fija fuy muy querida, Luçiana he por nombre, biva só e guarida.

Yo só la que tú sabes cómo te hove amado; 
yaziendo mal enferma venísteme con mandado, de tres que me pidién tú me aduxiste el dictado, yo te di el escripto qual tú sabes notado (587-588).

La identidad de Luciana está claramente configurada en el poema a través de la palabra, en particular la escrita y portadora de verdad, lo que resulta evidente en este recuento de su vida que posiciona el discurso en el mismo nivel que su nombre y su historia familiar.

Con respecto a Tarsiana, la palabra tiene en ella una impronta aún más destacada que en su madre, a pesar de que la escritura no se configure como el modo privilegiado de expresión de lo bueno y de lo verdadero. Sin embargo, incluso cuando no pueden asociarse efectivamente con la escritura, las palabras de la heroína se vinculan con un saber letrado que avala su emisión oral. Es lo que sucede con la oración que Tarsiana eleva a Dios antes de su muerte inminente a manos del rufián Teófilo; con su desempeño como juglaresa en Mitilene, cuando no solo canta para alegrar a su público, sino que cuenta su propia historia de forma oral pero apropiadamente rimada; y con las adivinanzas que la joven le propone a Apolonio como juego intelectual para quitarle la pesadumbre.

El carácter letrado de la sabiduría de Tarsiana, que sustenta su desempeño virtuoso, musical e intelectual en conjunto, es asumido tempranamente por la descripción que hace el poeta de su formación infantil y juvenil:

Quando a XII años fue la dueña venida, sabiá todas las artes, era maestra complida; de beltad conpañera non avié conoscida, avié de buenas mañas toda Tarso vencida.

Non querié nengún día su estudio perder, ca avié voluntat de algo aprender; maguer mucho lazdrava cayóle en plaçer, ca preciávase mucho e querié algo valer (352-353).

La asociación sabiduría letrada-virtud ilimitada, como eje de la heroicidad de Tarsiana, se esclarece en la primera prueba significativa que asume como parte de su aventura individual: el intento de asesinato por parte de Teófilo. Ante la proximidad de su propia muerte, la joven le pide al rufián que le deje rezar una oración a Dios.

Teófilo había arribado mientras Tarsiana "leyé su matinada" (377a), y el carácter letrado de su rezo se continúa de esa manera en la oración personal que le dirige a Dios posteriormente: 
Enclinóse la dueña, començó de llorar:

"Señor, dixo, que tienes el sol a tu mandar

e fazes a la luna creçer e enpocar,

Señor, tú me acorre por tierra o por mar.

Só en tierras ajenas, sin parientes criada, la madre perdida, del padre non sé nada; yo, mal non meresciendo, he a ser martiriada; Señor, quando lo tú sufres só por ello pagada.

Señor, si la justiçia quisieres bien tener, si yo non lo merezquo por el mio mereçer, algún consejo tienes para mí acorrer, que aqueste traidor non me pueda vençer" (381-383).

La sabiduría humana de sus palabras se conjuga con la sabiduría divina que ella reconoce como verdad, destacándose la referencia al martirio como la medida de la santidad de esa confluencia entre lo humano y lo divino, el saber terreno y el consejo sobrenatural que la acorre.

Ya como juglaresa en Mitilene, la palabra se convierte en el instrumento concreto mediante el cual la joven logra preservar su virginidad, incluso en el ámbito del prostíbulo al que había sido confinada luego de ser secuestrada por unos piratas y vendida alli . Las asociaciones entre palabra y santidad se incrementan en este punto y, aunque esa palabra se manifiesta en la oralidad del desempeño juglaresco, la calidad letrada que la avala se esclarece en la descripción de la maestría de Tarsiana y su desempeño musical.

Además de cantar de manera tan agradable como eficiente ("Començó unos viesos e unos sones tales / que trayén grant dulçor e eran naturales", 427ab), la doncella recita su propia historia ("tornóles a rezar un romançe bien rimado / de la su razón misma por ó haviá pasado", 428cd), esta historia, tanto en su referencia al cuidado técnico como a lo ya narrado por el poeta, remite sin duda a la escritura de clerecía como práctica letrada que la heroína reproduce, más allá de su estricta manifestación oral ${ }^{8}$.

\footnotetext{
${ }^{7}$ Como señala en su descripción de Tarsiana como una juglaresa muy especial, Musgrave declara que "Thus Tarsiana's escape from prostitution by becoming a pseudo-juglaresa reflects one of the themes of the work, the hero (or heroine) overcoming danger not only through virtue and faith, but also through education and intelligence" (1976: 136).

${ }^{8}$ De modo extensivo, podría pensarse también en una manifestación semejante del Libro de Apolonio como tal, cuya composición escrita no estaría reñida con su lectura en voz alta y su ejecución oral, sino todo lo contrario.
} 
Los vínculos de la palabra de Tarsiana con la santidad se reiteran asimismo en su encuentro con Apolonio, previo a la anagnórisis entre ambos como padre e hija. Esa palabra se destaca como lo más distintivo de la doncella ("por la palabra sola, luego de la entrada, / fue de los pelegrinos bien quista e amada", 485cd) y se compara con hierbas y medicinas curativas en su poder taumatúrgico ("yo trayo letuarios e espeçia tan sabrida / que, si mortal non fuere o que seya de vida, / yo le tornaré alegre tal que a comer pida", 488b-d). Son concretamente las adivinanzas, aquí como una serie y no de manera singular como habían sido emitidas antes, las que cierran el ciclo iniciado por la partida de Apolonio de Tiro, a través del reencuentro familiar. Este ciclo, abierto por la palabra funesta que escondía el pecado, concluye con la palabra que en principio encubre la verdad del vínculo padre-hija pero que conduce finalmente a su develamiento.

El innegable carácter letrado del juego de pregunta-respuesta entre Tarsiana y Apolonio pone de relieve, nuevamente, la naturaleza doble de la adivinanza: entre lo culto y lo popular, el registro escrito 9 y la oralidad; y también entre lo general y lo particular, lo que se destaca en la adivinanza de Tarsiana acerca de la pelota, a la cual Apolonio responde refiriéndose al origen de su historia en Pentápolis y, por extensión, a la ascendencia de la doncella:

"De dentro só vellosa e de fuera raída, siempre trayo en seno mi crin bien escondida; ando de mano en mano, tráenme escarnida; quando van a yantar negún non me conbida".

“Quando en Pentápolin entré desbaratado, si non fuesse por essa andaría lazdrado;

fuy del rey Architrastres por ella onrado, si no, non me oviera a yantar conbidado" (518-519).

La asociación entre la palabra sabia, propia de las adivinanzas, y la sabiduría de la historia vivida de manera personal conduce, de esta forma, a la revelación de la propia identidad en tanto verdad. Así, Tarsiana recupera su identidad mediante la palabra; una palabra vinculada a la escritura de su pasado, que la ha preservado del mal y ha definido su camino virtuoso.

9 "Although the number varies, the riddles themselves all derive ultimately from the enigmas of Symphosius, one of the main sources for medieval riddle-collections. He is the source for Tharsia's riddles in HART and in most succeeding versions of the Apollonius story" (Clark 1976: 32). 
Como señala Kelley, "The saints and individuals who secure divine sympathy invariably speak and write effectively, communicate truthfully, teach accurately, and have access to an unusually clear communicative connection with God" (2004: 68). Todas estas características del lenguaje de la santidad son reconocibles en Luciana y Tarsiana como heroínas cuya defensa virtuosa las acerca a un ideal santo femenino medieval. De manera contraria, los personajes asociados al mal, y aquí particularmente las mujeres que han sido objeto de análisis, se caracterizan por un lenguaje engañoso o mentiroso, en el que las palabras se usan mal y se relacionan con un espacio privado del consejo y cuidado femeninos que ambas (el aya de la hija de Antíoco y Dionisa) traicionan.

La custodia de la palabra de las mujeres, avalada en particular por la autoridad de san Pablo en el Nuevo Testamento (I Tim., 2, 12; I Cor., 14, 34-35), determina su confinación al espacio privado. Esto facilita la perpetuación del secreto, en el caso de la nodriza de la hija incestuosa del rey Antíoco, y los celos que Dionisa no es capaz de reconocer externamente pero sí de sentir en su interior y que determinan sus planes también secretos de asesinar a Tarsiana.

Frente a la norma del lenguaje masculino, el femenino se concibe o bien como ideal asociado al silencio o la moderación, o bien como defecto o desviación. La falsedad y el engaño, características básicas que han podido apreciarse en las palabras de la nodriza de la joven hija de Antíoco y de Dionisa como madrastra de Tarsiana, configuran textualmente un lenguaje de las mujeres asociado al mal y al pecado. Solo la virtud extrema, referida de manera muy próxima a la santidad en los personajes de la esposa y de la hija del héroe del Libro de Apolonio, se ha revelado capaz de doblegar esas palabras femeninas del mal.

A comienzos del siglo XIII, en Castilla, el movimiento poético conocido como "mester de clerecía" traduce materias y tradiciones previas y las adapta al contexto hispánico. Más allá de los particularismos, sin embargo, prima un contexto europeo en el cual las diferentes lenguas vernáculas desarrollan una literatura que busca acercar la doctrina cristiana a públicos más amplios que los que entonces permitía el latín. De allí que las obras paradigmáticas de la clerecía castellana del período sean los textos hagiográficos de Gonzalo de Berceo y poemas de materia antigua como el Libro de Alexandre y el Libro de Apolonio, que reformulan la heroicidad según la medida de una ética cristiana preeminente. Para esa clerecía, la palabra $-\mathrm{y}$, esencialmente, la palabra escrita- define su tarea y permite mediar entre la tradición latina y la vernácula, entre lo aprendido y lo que debe enseñarse a públicos más extendidos.

En el Libro de Apolonio esa palabra escrita y su carácter casi santo, o ligado a la santidad mediante la alianza de lo verdadero y lo virtuoso, se desarrolla particularmente en las figuras heroicas femeninas del texto, alejadas por tanto de 
cualquier referente histórico preciso en su carácter idealizado y opuestas a la visión generalizada de la mujer medieval. La desconfianza clerical hacia las mujeres y la concepción negativa de la palabra femenina se plasman en el resto de las mujeres del poema, en todo opuestas a la perfección modélica de Luciana y Tarsiana y representantes de la maldad mediante su accionar, pero, sobre todo, a través de un discurso ligado a la mentira y la falsedad como sus distintivos básicos.

\section{Referencias bibliográficas}

BROZYNA, Martha A., Gender and sexuality in the middle ages: a medieval source documents reader. Jefferson, NC: McFarland, 2005.

Casagrande, Carla, "La mujer custodiada". En: Duby, Georges; Perrot, Michelle (dirs.), Historia de las mujeres en Occidente. La Edad Media. Tomo 2. Madrid: Taurus, 1992, pp. 93-131.

Clark, Doris, "Tarsiana's Riddles in the Libro de Apolonio". En: Deyermond, A. D. (ed.), Medieval Hispanic Studies Presented to Rita Hamilton. London: Tamesis, 1976, pp. 31-43.

DesING, Matthew V., "Luciana's story: Text, Travel, and Interpretation in the Libro de Apolonio". En: Hispanic Review, 79, 1, 2011, pp. 1-15.

Deyermond, Alan, "Motivos folklóricos y técnica estructural en el Libro de Apolonio". En: Filologia, 13, 1968-69, pp. 121-149.

__ "Emoción y ética en el Libro de Apolonio". En: Vox Romanica, 48, 1989, pp. 153-164.

KELLEY, Mary Jane, “Ascendant Eloquence: Language and Sanctity in the Works of Gonzalo de Berceo”. En: Speculum, 79, 2004, pp. 66-87.

LÓPEZ IZQUIERDO, Marta, "Palabras de reinas, santas y alcahuetas. Modalización y representación del discurso femenino en la literatura medieval". En: Cabiers d'Études Hispaniques Médiévales, 27, 2004, pp. 83-94.

Musgrave, J. C., "Tarsiana and Juglaría in the Libro de Apolonio". En: Deyermond, Alan (ed.), Medieval Hispanic Studies Presented to Rita Hamilton. London: Tamesis, 1976, pp. 129-138.

PASTOR DE TOGNERI, Reyna, "Sombras y luces en la historia de las mujeres medievales". En: Ruano, E. B. (coord.), Tópicos y realidades de la Edad Media. Madrid: Real Academia de la Historia, 2000, pp. 179-230.

RicO, Francisco, "La clerecía del mester". En: Hispanic Review, 53, 1985, pp. 1 $23 ; 127-150$.

SCHAUS, Margaret, Women and gender in medieval Europe. An enciclopedia. New York: Routledge, 2006.

URíA MAQUA, Isabel, Panorama crítico del mester de clerecía. Madrid: Castalia, 2000. 
CARINA ZubiLlaga

WEISS, Julian, The "Mester de Clerecia": Intellectuals and Ideologies in Thirteenth-Century Castile. Woodbridge: Tamesis, 2006.

Zubillaga, Carina, Poesía narrativa clerical en su contexto manuscrito. Estudio y edición del Ms. Esc. K-III-4 ("Libro de Apolonio", "Vida de Santa María Egipciaca”, "Libro de los tres reyes de Oriente"). Buenos Aires: SECRIT, 2014.

_-, "La voz de las mujeres en el Libro de Apolonio". En: Mirabilia, 29, 2, 2019, pp. 13-28. 